\title{
RELATOS DE MÃES OUVINTES SOBRE OS PROCESSOS COMUNICATIVOS COM FILHOS SURDOS
}

\author{
RELATOS DE MADRES OYENTES SOBRE LOS PROCESOS DE COMUNICACIÓN \\ COM HIJOS SORDOS
}

\author{
HEARING MOTHERS REPORT ABOUT THE PROCESS OF COMMUNICATION \\ WITH DEAF CHILDREN
}

\author{
Lidiane Augusta Ferrari BOTTEON ${ }^{1}$ \\ Maria Lucia Oliveira Suzigan DRAGONE ${ }^{2}$
}

RESUMO: Este estudo tem o objetivo de caracterizar os processos de comunicação entre mães ouvintes e filhos surdos no lar. Participaram deste estudo três mães ouvintes com filhos surdos em idade escolar. Para a coleta dos dados, foram realizadas entrevistas em áudio gravadas com as mães. Os resultados apontaram que as mães ouvintes fazem uso constante da linguagem oral e de gestos caseiros para se comunicarem com as crianças surdas e consideram os processos de comunicação satisfatórios, embora algumas vezes difíceis. A negação da condição de surdez encontra-se nas entrelinhas das respostas e revelou-se a expectativa de que as crianças venham a ouvir e falar para melhor se desenvolverem. Evidenciou-se que não houve menção pelas mães da possibilidade de comunicação por Língua de Sinais com seus filhos surdos, o que poderia favorecer o desenvolvimento da linguagem e da aprendizagem das crianças.

PALAVRAS-CHAVE: Surdez. Comunicação. Família. Aprendizagem.

RESUMEN: Este estudio tiene el objetivo de caracterizar los procesos de comunicación entre la madre oyente y el hijo sordo en el hogar. Participaron de este estudio tres madres oyentes con hijos sordos en edad escolar. Para recoger las informaciones fueron realizadas encuestas audios grabadas con las madres. Los resultados apuntaron que las madres oyentes hacen uso del lenguaje oral y de los gestos caseros para se comunicaren con los niños sordos y consideran los procesos de comunicación satisfactorio, todavía algunas veces difíciles. La negación de la condición de sordez encuéntrase en entre líneas de las respuestas se reveló la expectativa de que los niños vengan a escuchar y hablar para mejor desarrollo. Quedó claro que no hubo mención por las madres de la posibilidad de comunicación por lengua de señales con sus hijos sordos, lo que podría favorecer el desarrollo del lenguaje y aprendizaje de los niños.

PALABRAS CLAVE: Sordez. Comucicación. Familia. Aprendizaje.

${ }^{1}$ Centro Universitário Padre Albino (UNIFIPA), Catanduva - SP - Brasil. Docente no curso de Pedagogia. Mestrado em Educação (UNIARA). ORCID: http://orcid.org/0000-0003-4479-268X. E-mail: lidi_ferrari@hotmail.com

${ }^{2}$ Universidade de Araraquara (UNIARA), Araraquara - SP - Brasil. Docente nos cursos de Pedagogia presencial e $\mathrm{EaD}$ e no Programa de Pós-Graduação em Processos de Ensino, Gestão e Inovação. Doutorado em Educação Escolar (UNESP). ORCID: https://orcid.org/0000-0002-4567-0679. E-mail: mldragone@uniara.com.br 
ABSTRACT: This study aims to describe the process of communication between hearing mothers with and deaf children at home. This study counted on the participation of three hearing mothers with deaf kids of school age. For the collecting of data, audio-recorded interviews were conducted with mothers. The results showed that mothers make constant use of speech and familiar (homemade) gestures to communicate with deaf children and they consider the communication processes satisfactory, although sometimes difficult. The nonacceptance of their deafness condition can be found between the lines in their answers because the expectation was revealed that the children will hear and speak to achieve a better development. It was evident that there was no mention from the mothers to the possibility of communication by Sign Language with their deaf children, what could favor the language development and the children's learning.

KEYWORDS: Deafness. Communication. Family. Learning.

\section{Introdução}

A criança é significada e ressignificada na fala da mãe e é, a partir da alienação, ou não, a esse lugar materno que a criança irá se constituir, segundo a psicanálise francesa, a partir de Lacan, conforme referido por Lieber (2015). Além disso, em sendo a Língua de Sinais uma língua diferente da utilizada pelas mães ouvintes com filhos surdos, faz com que essas mães tenham a sensação de serem imigrantes dentro de seus lares (FORMIGONI, 2004), por não conseguirem se comunicar, conduzindo-as a não aceitarem essa situação.

O impacto que ocorre e envolve os pais no momento da descoberta da surdez de seus filhos causa, inicialmente, um distanciamento entre eles, seja pela surdez em si ou pela fuga, o que faz com que a criança surda seja prejudicada em seu processo de formação biopsicossocial desde a primeira infância, o que acaba por comprometer toda sua vida. Para suprir esse prejuízo, há a necessidade fundamental do conhecimento da Língua de Sinais, como forma de comunicação entre pais ouvintes e filhos com surdez. O distanciamento dos familiares no processo de comunicação com o sujeito surdo é a primeira barreira linguística com implicações na inclusão social e no desenvolvimento de linguagem do sujeito surdo (FRANCO, 2015).

As interações humanas se iniciam no âmbito familiar, que, por ser considerado como a primeira escola, onde as capacidades das crianças são desenvolvidas, torna-se o local ideal para se iniciar o desenvolvimento de base para os surdos. Tavares (2011) refere que há a possibilidade do aproveitamento de todas as oportunidades de estimulação geradas no lar, no caso de pais preparados e mães conscientes de seu papel de acolhimento e de interação com o filho surdo. Dessa forma, a compreensão dos pais sobre a surdez é primordial para a qualidade 
na formação de seus filhos surdos, uma vez que o processo de aquisição de linguagem é uma constituição subjetiva da criança, iniciada desde os primeiros laços de interação com a mãe.

Neste contexto, observa-se a necessidade de compreender como ocorrem as experiências comunicativas nas famílias com filhos Surdos, assim como, se têm ciência sobre as dificuldades geradas pelas prováveis barreiras com as falhas na comunicação. Entende-se que o conhecimento de métodos diferenciados e mais favoráveis para o desenvolvimento da comunicação com surdos seria essencial e contribuiria com as interações familiares fundamentais para o desenvolvimento das crianças surdas.

\section{Métodos para desenvolver a comunicação dos surdos: oralismo}

Desde 1878, quando ocorreu em Paris o I Congresso Internacional sobre a instrução de surdos, essa temática tem sido debatida. Nesse congresso foram defendidas duas frentes a respeito da comunicação dos surdos: a valorização de que a fala era melhor que utilizar gestos e a ideia de que os gestos também eram importantes para as crianças se comunicarem (FRANCO, 2015). Iniciou-se, além disso, a propagação da importância do papel da família na educação e integração social do surdo. Segundo Franco (2015, p. 37), “o evento também acarretou alguns ganhos civis para os surdos, como o direito de assinar documentos".

Em 1880, ocorreu em Milão o II Congresso Internacional sobre a instrução de surdos, quando houve muitas mudanças com relação à abordagem da educação de pessoas com surdez. A preparação desse congresso aconteceu a partir de uma maioria ouvinte e de surdos oralizados com o intuito de dar forças, no que dizia respeito à educação dos surdos. De acordo com Paiva (2000, p. 34) as principais considerações firmadas nesse congresso foram as seguintes:

[...] a superioridade incontestável da fala sobre os sinais para reintegrar os surdos-mudos na sociedade e para dar-lhes um melhor conhecimento de linguagem, o método oral puro deve ter preferência ao de sinais. [....] o uso simultâneo da fala e sinais tem a desvantagem de prejudicar a fala, a leitura orofacial, e a precisão de ideias, o método oral puro deve ser preferido.

Ficou decido, então, que a linguagem oral era superior às Línguas de Sinais e que, desta forma, os surdos deveriam aprender a falar. Ficou proibido o uso de quaisquer gestos ou Língua de Sinais. Assim, o mundo inteiro passou a utilizar o método oralista por, aproximadamente, cem anos, que foram chamados de cem anos de oralismo (LIEBER, 2015).

Fato é que os ouvintes são dominantes na sociedade. Dessa forma, a imposição ao oralismo como forma de comunicação com os surdos, além da crença de que os surdos 
poderiam se adaptar com facilidade e naturalidade à condição de ser surdo, indica compreender a surdez como uma condição orgânica com a possibilidade de ser curada e reabilitada no âmbito da "[...] pedagogia corretiva, instalada nos princípios do século XX" (SKLIAR, 2013, p. 7). Assim, a imposição da fala, visando a cura para que o surdo seja capaz de ouvir e falar, tem persistido no decorrer do tempo.

O oralismo é um método que, percebe a surdez como uma deficiência que deve ser minimizada pela fala, porém, essa se desenvolve por meio da estimulação auditiva. Entendese que essa estimulação possibilita a fala e faz com que a criança surda integre-se na comunidade ouvinte. Assim, é possível dizer que o objetivo do oralismo é fazer uma reabilitação auditiva na criança surda em direção à normalidade da fala.

Segundo Goldfeld (1997), o oralismo ou filosofia oralista visa à integração da criança surda na comunidade de ouvintes, dando-lhe condições de desenvolver a linguagem oral, no caso do Brasil, o português. A ideia de linguagem para a maioria dos profissionais dessa filosofia restringe-se a linguagem oral e para eles, essa deve ser a única forma de comunicação para os surdos.

Os dados encontrados na literatura sobre o oralismo mostram que durante a infância os surdos, estimulados a usar a oralidade, na maioria das vezes, não possuem uma boa compreensão daquilo que lhes é dito. O método oralista tem uma visão do surdo como alguém deficiente que necessita, a qualquer custo, aprender uma língua oral, que possibilite sua aceitação na sociedade em geral.

As dificuldades geradas pelas barreiras de comunicação do surdo com sua família, tais como a ausência de uma língua partilhada, a insistência da utilização da linguagem oral, a utilização de gestos indicativos ou compreendidos somente no lar, em detrimento do uso da língua de sinais, desde a primeira infância e nos primeiros anos de vida escolar, faz com que o surdo fique em desvantagem em relação ao ouvinte, pois este faz uso de sua língua materna desde seu nascimento e adquire conhecimento e informações relevantes para seu desenvolvimento através de uma língua partilhada por seus familiares.

\section{A importância da mãe para o desenvolvimento emocional da criança no primeiro ano de vida}

Segundo Winnicott (1993), a mãe exerce um papel fundamental no desenvolvimento da criança. Há algo na mãe de um bebê que a torna qualificada para proteger seu filho na fase de vulnerabilidade. A genitora é capaz de desempenhar esse papel ao sentir-se segura, amada 
em sua relação com o pai da criança e com a própria família, ao sentir-se aceita nos círculos cada vez mais amplos, que envolvem a família e constituem a sociedade e o amor pelo bebê.

A teoria winnicottiana contém uma série de proposições fundamentando o desenvolvimento da criança. A proposição inicial é de que há, no universo psicológico, uma tendência ao desenvolvimento que é inata ao ser humano, correspondendo ao crescimento do corpo e ao desenvolvimento gradual de certas funções. $O$ processo evolutivo do desenvolvimento emocional se assemelha ao sentar do bebê que, geralmente, ocorre por volta dos cinco ou seis meses de vida e ao andar, próximo dos doze meses. Mas, “[...] esse crescimento natural não se constata na ausência de condições suficientemente boas, e nessa dificuldade consiste em parte em estabelecer quais são essas condições" (WINNICOTT, 1993, p. 5). As condições que se encontram envolvem diversos aspectos das relações entre mãecriança na integração da personalidade.

Os primeiros estágios desse processo vitalício, ao qual Winnicott (1993) chamou de dolorosos, acontecem na primeira infância quando a mãe propicia ao bebê um ambiente facilitador para apresentar fragmentos da realidade, dependendo da fase desenvolvimento de seu filho, para capacitá-lo a lidar com a realidade. Isso ocorre na relação entre mãe e bebê, o que favorece a ocorrência do processo de integração. Caso não ocorra um ambiente propício entre mãe e bebê como, por exemplo, mãe muito nervosa, ansiosa ou deprimida, a relação necessária ficará prejudicada e dificultará a continuidade do processo. À medida que a relação entre mãe e bebê se desenvolve em ambiente propício, o bebê introjeta o ego auxiliar da mãe e, dessa maneira, torna-se capaz de ficar só sem apoio frequente da mãe ou de um símbolo da mãe.

Desta forma, compreende-se a importância da figura materna no processo de constituição satisfatória da criança no seu primeiro ano de vida. No entanto, é necessário que a mãe esteja em condições suficientemente boas, para que a interação aconteça e desencadeie a integração da personalidade e o desenvolvimento emocional da criança.

Nesse processo, uma língua partilhada por ambos é essencial, para tal, é preciso pensar na proposta do Bilinguismo ${ }^{3}$ para a comunicação dos Surdos. A utilização da Língua de Sinais, como primeira língua do Surdo, é a garantia do respeito à sua língua. Quando falamos em língua, não podemos esquecer que a língua não é apenas um conjunto de regras, mas, a

${ }^{3}$ Há duas formas distintas de definir a filosofia bilíngue. A primeira defende que a criança surda deve adquirir a Língua de Sinais e a modalidade oral de seu país e ser alfabetizada na língua oficial do seu país e a outra acredita ser necessário para o surdo aprender a Língua de Sinais e apenas a modalidade escrita da língua oficial do seu país (GOLDFELD, 1997). 
cultura das pessoas que a usam. O Surdo, ao entrar em contato com a comunidade surda e sua língua, passa a interagir de forma socioafetiva com seus pares por meio da Língua de Sinais e assim poderá perceber o mundo de forma mais autônoma. Paiva e Silva (2000) entendem que a criança surda pode ter a capacidade intelectual semelhante à das crianças ouvintes, desde que adquira e internalize uma língua desde pequena, promovendo assim, a evolução dos primeiros intercâmbios comunicativos sociais.

Embora haja diferenças culturais entre pais ouvintes e filhos surdos, segundo Goldfeld (1997), a solução mais apropriada para a comunicação satisfatória de crianças surdas parece ser mesmo o bilinguismo. No entanto, para assegurar o desenvolvimento lingú́stico e cognitivo é importante e necessário que convivam com a comunidade surda por meio de diálogo contextualizado pela Língua de Sinais.

É necessário compreender o quanto a interação entre a mãe ouvinte e o fillho surdo pode se encontrar prejudicada, no caso de não haver esse compartilhamento de linguagem. Segundo Winnicott (1993), o bebê precisa de uma mãe que favoreça seu desenvolvimento emocional, para tanto, ela necessita estar bem para criar ambientes propícios de interação. Se houver a negação da surdez, acompanhada da utilização linguagem oral e com base na ansiedade por uma comunicação oral entre a mãe e o filho, como isso pode impedir a criança de integrar-se nesse processo por meio da surdez? Em estágios posteriores, mostrados pela teoria, a mãe dependerá dos processos intelectuais do filho, expressos por meio de uma linguagem compartilhada para, aos poucos, readquirir sua vida própria. Portanto, se o filho demorar a expressar seus processos intelectuais na língua utilizada pela mãe, ocorrerá um prolongamento de relação de cuidado excessivo o que, consequentemente, poderá causar conflitos e atrasos no desenvolvimento emocional da criança surda.

\section{Método}

Uma pesquisa investigativa com caráter qualitativo, com projeto foi devidamente aprovado por Comitê de Ética em Pesquisa com seres humanos, via Plataforma Brasil (CAAE $\left.\mathrm{n}^{\circ} 1831115\right)$, cujo foco, voltado à compreensão de como ocorreram as experiências comunicativas de mães ouvintes no lar com seus filhos Surdos é abordado neste artigo. Foram convidados a participar mães ouvintes com filhos Surdos, residentes em uma cidade do interior do estado de São Paulo, levando em consideração como critérios de inclusão que as mães deveriam ser ouvintes e seus filhos Surdos em idade escolar, frequentando a educação infantil ou os anos iniciais do ensino fundamental. Foram contatadas quatro mães, porém, 
somente três aceitaram participar da pesquisa, ora denominados de forma fíctícia pela letra $\mathrm{M}$ e numerais (1, 2 e 3$)$.

$\mathrm{O}$ acesso às mães dos alunos surdos foi viabilizado pela Secretaria de Educação do Município e os primeiros contatos foram por telefone. Após o aceite inicial das mães, foi possível agendar datas e horários para que a pesquisadora fosse até a residência de cada uma delas, quando foram explicados os objetivos da pesquisa e solicitada autorização formal para a realização da entrevista individual, que se consolidou, em seguida, na própria residência, em local privado. As entrevistas foram áudio-gravadas e, devidamente, transcritas para se proceder ao levantamento dos temas mais recorrentes, a saber: modalidades de comunicação com seus filhos Surdos e eficácia do processo comunicativo.

Os roteiros das entrevistas foram elaborados pela pesquisadora. As perguntas exploram a importância da relação entre a concepção de surdez que os adultos detêm e o desenvolvimento psicossocial da criança surda. Foi considerando que a família e a escola representam os dois principais ambientes de desenvolvimento humano nas sociedades contemporâneas, que se buscou também identificar como mães ouvintes descrevem as formas de comunicação estabelecidas com seus filhos surdos na infância e suas expectativas sobre o desenvolvimento dessas crianças, além de compreender a eficácia do processo comunicativo no lar.

\section{A percepção de mães ouvintes sobre os processos comunicativos vivenciados no lar com seus filhos surdos}

Ao iniciar a entrevista todas as participantes mostraram-se ansiosas para falar sobre o assunto e as três foram esclarecedoras em suas respostas, sendo estas permeadas por lembranças, principalmente, sobre a descoberta da surdez de seus filhos.

Com relação à forma como acontece a comunicação entre as mães e seus filhos surdos, as mães foram unânimes em dizer que consideram normal, utilizar a linguagem oral, de forma semelhante à utilizada com outros interlocutores adultos ou crianças ouvintes. Em outras palavras, elas consideram o processo satisfatório. Duas delas citaram a utilização de gestos para complementar a comunicação em determinados momentos, mas sem fazer referência à LIBRAS e sim a gestos caseiros.

Com meu filho sempre procuro falar com a boca com ele, às vezes se eu percebo que ele não entende, às vezes, eu mostro o que eu quero e ai e, ele ouve o que eu estou falando pra ele (M1). 
Normalmente, como se eu tivesse aqui conversando com você, eu converso com ela, normalmente (M2).

Hoje normal. Ela fez implante com dois anos de idade e, iniciou a fono aos 6 meses de idade, com um ano ela só balbuciava. Ela começou a ouvir com três anos, nesta fase a comunicação era através de gestos caseiros (M3).

Ao se referirem ao ouvir, ter audição normal, como algo necessário para o processo de comunicação, as respostas das mães corroboraram a forte influência da pedagogia corretiva, instaurada no século XX, na qual os Surdos se encaixariam em um modelo de medicalização da surdez, visto mostrarem a expectativa de seus filhos poderem ser curados e passarem a ouvir. Deve-se aqui, ressaltar que foram mais de cem anos tentando a correção e a normalização na educação de surdos, com instituições especiais reguladas pela caridade e beneficência na busca da cura da surdez (SKLIAR, 2013). Nessa perspectiva, manteve-se a cultura social de controlar, separar e negar a existência da comunidade surda, da Língua de Sinais, das identidades surdas e das experiências visuais, que determinam o conjunto de diferenças dos surdos em relação a qualquer outro grupo de sujeitos.

Quando as mães enfatizaram em suas respostas a utilização da linguagem oral, como exclusiva com seus filhos surdos, elas revelaram não procurar outras formas de aproximação comunicativa ao alcance de surdos. Portanto, provavelmente, as mães tiveram processos pouco satisfatórios de comunicação com os filhos e, consequentemente, de interação mãe e filho na primeira infância. Evidenciou-se um provável déficit na questão do desenvolvimento emocional da criança, que ocorre a partir da presença constante de condições suficientemente boas nos diversos aspectos das relações entre a mãe e a criança (WINNICOTT, 1993); sendo que as interações humanas são permeadas pela linguagem, que oferece o significado das coisas concretas ou não presentes no contexto da criança (VYGOTSKY, 1998).

Em decorrência da indagação direta sobre como as mães avaliavam a interação comunicativa entre elas e seus filhos, as respostas foram bastante firmes com relação às interações comunicativas serem satisfatórias, em quaisquer circunstâncias. Com essa assertividade, as mães deixaram clara a não aceitação da surdez, acreditando que as crianças entendiam tudo com o uso da linguagem oral.

As falas das mães deixaram evidente a negação feita quanto à surdez. M1 destaca não ter plena convicção de que o processo de comunicação tem sido satisfatório, pois, embora ache que o filho entende tudo, associa essa compreensão ao aprendizado obtido na escola e se distancia das interações no lar. M2 mostrou-se insegura na resposta e revelou contradições com a resposta anterior, na qual apontou que indicava objetos quando a criança não 
compreendia a mensagem, indicando que sempre a filha escuta e compreende, mesmo à distância, o processo é satisfatório. M3 relata falar normalmente com a filha e destaca que ela compreende tudo, inclusive quando assiste à televisão, mas músicas a filha surda não acompanha por questões de ritmo. Nesse caso, M3 dá indícios de que a compreensão da filha com a oralidade é satisfatória, sendo a única exceção à percepção de músicas.

Eu acho que sim, ele entende tudo. Ele aprendeu muito esse ano passado na escola (M1).

Sim, muito, muito, a gente é muito... (Entrevistadora: mas ela entende tudo o que a Sra. fala, ou a Sra. precisa as vezes mostrar?) Não, ela entende tudo o que eu falo. Entrevistadora: e quando a Sra. fala com ela de longe é preciso chegar mais perto?) Normalmente, como tivesse conversando com você eu converso com ela. (Entrevistadora: se a Sra. estiver em um cômodo da casa e ela em outro, ela entende ou a Sra. tem que chegar mais perto?) Mesmo que tá longe ela entende (M2).

Sim, hoje falamos com ela normal, em casa tudo é normal ao assistir televisão ela compreende tudo, mas música ela ouve e não compreende a letra, não consegue acompanhar o ritmo por ser muito rápido (M3).

Mesmo ao serem indagadas mais objetivamente sobre a possibilidade de utilizarem formas diferentes de comunicação para conseguir compreender melhor seus filhos surdos, as mães mantiveram falas semelhantes às já citadas nas questões anteriores, ignorando a possibilidade de utilização de Libras e esperando que os filhos as compreendessem por linguagem oral ou gestos caseiros. Isso deixa claro não terem outras estratégias de comunicação. Opinião essa reforçada por M3, ao dizer que com a oralidade desenvolvida pela filha propiciou melhoria no processo de comunicação.

Não, só a fala e mostrar o objeto, o que tem que ser feito (M1).

Não, não precisa tudo normalmente (M2).

Quando ela não era oralizada, tinha que ficar frente a frente para falar com ela, atualmente, não (M3).

Com certeza, caso a linguagem oral e os gestos indicativos não produzam uma comunicação plenamente satisfatória, conforme parece ocorrer segundo as respostas obtidas, a interação mãe ouvinte e filho Surdo fica prejudicada. Em sendo assim, a compreensão efetiva entre mãe ouvinte e filho surdo, muito importante na questão da afetividade entre ambos, essencial para o desenvolvimento, também terá prejuízo. Entende-se que o desenvolvimento da criança não é estático no contexto em que ocorre e nem fixo em si mesmo, está sempre em um estado de transformação em relação à idade da criança e às necessidades em constante mutação. Para tanto, isso depende das condições necessárias de um processo afetivo de 
interação entre a mãe e o filho para o crescimento individual da criança (WINNICOTT, 1993). Neste caso, os processos de comunicação descritos pelas mães podem ter sido deficitários. Na falta de processos de comunicação realmente satisfatórios e efetivos, necessários para a interação entre a mãe e o filho, podem ocorrer prejuízos relevantes no desenvolvimento emocional e, consequentemente, no global da criança.

Destaca-se, também, como um dado relevante nas respostas analisadas das mães a não aceitação da surdez, evidenciada pelas tentativas constantes de que a criança ouça por diversas formas, compreenda a linguagem oral e pela falta de referência à utilização da Língua de Sinais, as mães não cogitaram utilizar a Libras com seus filhos Surdos. Esse posicionamento revela a crença de que crianças que usam a LIBRAS são desqualificadas, perante aquelas que aprendem a falar, como destacado por Schiavon (2012). É necessário realçar que Libras é considerada uma língua e que todas as crianças surdas podem adquirir a Língua de Sinais desde que participem das interações cotidianas com a comunidade surda.

Paiva e Silva (2000) sinalizam que há uma visão clínico-terapêutica na questão da surdez, ou seja, os surdos são vistos como tendo uma deficiência auditiva, a qual deve ser curada para que eles possam se aproximar do normal, o ouvinte. Nessa perspectiva, caso não se oriente corretamente os familiares, ocorre um prejuízo para os surdos com perdas auditivas severas e profundas, devido às dificuldades na compreensão e no uso da língua na modalidade oral e passam a apresentar rendimento muito baixo em todos os aspectos do desenvolvimento.

Sob a ótica das mães ouvintes, participantes desta pesquisa, o processo comunicativo ocorre, predominantemente, por meio da linguagem oral, na oralidade e com uso de gestos habituais. Na percepção das mães não há prejuízos para o processo comunicativo, pois, na maioria das vezes, consideram-no como eficiente. No entanto, dois elementos emergem dessas percepções: a falta de informação sobre a importância da aquisição da Língua de Sinais desde a primeira infância para evitar atrasos de linguagem nas crianças surdas e a não aceitação da surdez pela negação dessa condição na espera que a audição e a fala vão se desenvolver e tudo caminhará para a normalidade, ou seja, para a utilização da linguagem oral.

A literatura aponta que, a aquisição da Língua de Sinais pelos Surdos, defendida pelo Bilinguismo, pode ser adquirida mais naturalmente pela criança surda, que passará a desenvolver-se linguística e cognitivamente sem dificuldades (SKILIAR, 2003; PAIVA; SILVA, 2000; LACERDA, 1998; GOLDFELD, 1997). Desta forma, pode ser possível evitar atrasos na linguagem, além de melhorar todas as intercorrências tais como: percepção, 
formação de conceitos, atenção e memória, desde que a introdução à Língua de Sinais ocorra em idade semelhante àquela que criança ouvinte adquire a língua oral.

\section{Considerações finais}

Evidencia-se que as mães ouvintes de crianças surdas fazem uso constante da linguagem oral e utilizam gestos caseiros para se comunicarem. Esse comportamento conduz a uma comunicação insatisfatória, embora as mães erroneamente não a considerem assim. É fato que algumas mães buscaram mudar de estratégia de comunicação ao perceberem dificuldades de compreensão pelas crianças, mas, talvez até por falta de conhecimento, continuaram utilizando a oralidade como via de principal e não houve menção à utilização da Língua de Sinais. A raiz inicial dessas atitudes pode estar na não aceitação da condição de surdez, induzindo a necessidade de buscar a normalidade da audição e da fala. A participação de seus filhos Surdos nas comunidades Surdas e a utilização da Língua de Sinais, no lar, poderiam minimizar essas dualidades e favorecer os processos de comunicação tão necessários nas interações mãe e filho.

Em relação à condição da surdez, ficou claro que mães esperam a normalidade por meio do desenvolvimento da fala e do desenvolvimento da audição, pois quando as crianças falavam ou escutavam com auxílio de amplificação sonora individual, mesmo que não houvesse comunicação plena, as mães consideravam normais e se sentiam satisfeitas. As mães entrevistadas esperam que seus filhos surdos ouçam e falem.

É possível entender, neste estudo, que o bilinguismo está longe de acontecer de forma plena, pois mães não se posicionaram em favor da Língua de Sinais como forma de comunicação com filhos surdos. Nota-se que a falta de conhecimento sobre os benefícios da aprendizagem da Língua de Sinais desde a primeira infância para indivíduos surdos ainda é um entrave para o desenvolvimento satisfatório deste indivíduo. Ocorre o caminho inverso ao que o Bilinguismo defende, pois primeiro os pais buscam, a todo custo, o aprendizado da linguagem oral e o desenvolvimento da audição e não o aprendizado da Língua de Sinais como primeira língua, desconhecendo que por meio do conhecimento da Língua de Sinais se processaria o desenvolvimento da língua portuguesa na modalidade escrita e oral.

\section{REFERÊNCIAS}

GOLDFELD, M. A criança surda: linguagem e cognição numa perspectiva sóciointeracionista. São Paulo: Ed. Plexus, 1997. 171 p. 
LACERDA, C. B. F. Um pouco da história das diferentes abordagens na educação dos surdos. Cadernos Cedes, Campinas, v. 19, n. 46, p. 68-80, set. 1998. DOI:

http://dx.doi.org/10.1590/S0101-32621998000300007

LIEBER, S. N. Aspectos da constituição de uma criança surda pela fala do ouvinte: Entre traços e significantes. 2015. 119 f. Dissertação (Mestrado em Fonoaudiologia) - Pontifícia Universidade Católica de São Paulo, São Paulo, 2015.

NEVES, R. T. Políticas Públicas de Inclusão de alunos com deficiência de 1994 a 2014 : limites e perspectivas na inclusão de alunos surdos no município de Colombo-PR. 2016. 141 f. Dissertação (Mestrado em Educação) - Universidade Tuiutí do Paraná, Paraná, 2016.

PAIVA, A. B. S. O aluno surdo na escola regular: imagem e ação do professor. 2003. 103 f. Dissertação (Mestrado em Psicologia) - Universidade Estadual de Campinas, Campinas, 2000 .

SCHIAVON, D. N. Prática pedagógica com alunos surdos: sala de recursos e classe comum. 2012. 111 f. Dissertação (Mestrado em Educação) - Universidade Estadual Paulista, Araraquara, 2012.

SKLIAR, C. A surdez: um olhar sobre as diferenças. 6. ed. Porto Alegre: Mediação, 2013. $189 \mathrm{p}$.

TAVARES, M. Os efeitos do diagnóstico nos pais da criança surda: uma análise discursiva. 2001. 181 f. Dissertação (Mestrado em Fonoaudiologia) - Pontifícia Universidade Católica de São Paulo, São Paulo, 2001.

VYGOTSKY, L. S. Pensamento e linguagem. Trad. Jefferson Luiz Camargo. Rev. José Cipolla Neto. 2. ed. São Paulo: Martins Fontes, 1998. 169 p.

WINNICOTT, D. W. A família e o desenvolvimento individual. Trad. Marcelo Brandão Cipolla. São Paulo: Martins Fontes, 1993. 247 p.

\section{Como referenciar este artigo}

BOTEON, L. F.; DRAGONE, M. L. O. S. Relatos de mães ouvintes sobre os processos comunicativos com filhos surdos. Temas em Educ. e Saúde, Araraquara, v. 17, n. 00, p. e021005, 2021. e-ISSN 2526-3471. DOI: https://doi.org/10.26673/tes.v17i00.14665

Submetido em: $24 / 01 / 2021$

Revisões requeridas: 15/02/2021

Aceito em: 23/03/2021

Publicado em: 20/04/2021 